\title{
CUANDO VIAJAR NO ES UN PLACER: El divorcio en vacaciones
}

\author{
Maximiliano E. KORSTANJE \\ Universidad de Palermo (Argentina) \\ maxikorstanje@arnet.com.ar
}

\section{WHEN TRAVELLING IS NOT FUNNY: The divorce in the holidays}

Resumen: En los últimos años los especialistas en psicología y los terapeutas, se han dado cuenta que existe un cambio en los patrones de conducta en el veraneante cuando debe ser reinsertado en su vida laboral cotidiana. Estos cambios van desde la depresión hasta el divorcio, y han sido clasificados como "síndrome post-vacacional". Si bien, por un lado, la cantidad de síntomas de este síndrome hace muy difícil el reconocimiento por parte de la academia, la realidad es que parece existir una relación directa entre el divorcio, siempre un fenómeno en ascenso, con las vacaciones y el turismo. El presente trabajo de investigación reúne evidencia que no solo refuta dicha hipótesis sino que pone en cuestionamiento las bases conceptuales del stress

Abstract: post-vacacional.

In last years, some specialists and therapists have acknowledged travellers showed a change in their behaviour after their holidays, precisely when the tourist is rechanneled in the humdrum routine of its working life. These psychological changes range from depression to divorce, and all them was labeled as "post vacation syndrome". Even if, the symptomatology of this syndrome is very hard to be measured, some experts believe there is strong connection between divorce and holidays. The present short investigation not only collects evidence to

Palabras clave: reject this belief, but also gives an alternative explanation to the post-vacation syndrome.

Stress; Vacaciones; Placer; Divorcio; Viaje turístico

Distress; Vacations; Pleasure; Divorce; Tourist travel 


\section{Introducción}

Las estadísticas respecto a la cantidad de divorcios va en aumento; no solo las familias se encuentran en un proceso de cambio abrupto por las uniones temporales, sino que además el 50\% de ellas en Estados Unidos hoy representan una segunda unión, es decir exhiben un divorcio previo. El promedio de duración de un matrimonio va de 3 a 7 años ${ }^{1}$. Ello genera consecuencias negativas que van desde la agresividad con la ex pareja, hasta un menor tiempo con los hijos. En la Argentina las cifras siguen el mismo patrón, a la vez que uno de cada tres matrimonios se divorcian, el $60 \%$ de las rupturas está impulsada por las mujeres. Según las causas (en 5500 casos relevados), el 43\% acusa a su cónyuge de injurias graves, mientras el 38\% aduce abandono de hogar. Sólo el 13\% declara adulterio como causa principal de separación ${ }^{2}$. Otras fuentes revelan que se da en Argentina un divorcio cada media hora $^{3}$. Se estima por fuentes no oficiales, que uno de cada tres divorcios se inicia luego de las vacaciones ${ }^{4}$.

Dentro de esta coyuntura, uno se pregunta si ¿el viaje vacacional representa un factor de unión, como impone el imaginario colectivo o por la presión que implica organizar un viaje, es el desencadenante?. Muchas parejas en crisis optan por tomar un viaje reparador a un destino paradisíaco para solucionar sus problemas maritales, empero ¿que pasaría si la relación fuese totalmente inversa?, ¿Por qué?

Los objetivos de la siguiente investigación versan en

1. Describir en la ciudad de Buenos Aires, las características demográficas de los divorciados.

2. Establecer cual es la relación entre divorcio y vacaciones.

3. Comprender el rol del viaje turístico como unificador o disgregador de la pareja.

Las separaciones sucedidas luego de las vacaciones son tan comunes que han recibido un nombre por parte de la psicología aplicada, "síndrome post-vacacional”. La misma consiste en la manifestación de stress y ansiedad luego del regreso al trabajo producto del final de las vacaciones. Un ajuste de tipo cognitivo pone el sujeto frente a un estado de depresión, que puede acelerar la crisis marital pre-existente. Durante este lapso de re-acomodamiento, las decisiones se encuentran sesgadas por atajos "cognitivos" 5 . El mundo ideal interno del consumidor, donde las reglas se someten a la propia voluntad genera un gran contraste con la obligación que recae sobre el trabajador. Estos desajustes en la persona para integrar el mundo del trabajo con el ocio, pueden ser algunos de los factores que coadyuvan en la decisión de divorciarse. Por desgracia, el síndrome carece de aceptación dentro de la comunidad científica pues es difícil articular una medición fiable que lleve al diagnostico. Nuestro aporte, va en ese sentido, orientado a presentar estadística general suficiente para probar que una cantidad de divorcios se sucede producto del stress post-vacacional.

1 Fuente. Las Alarmantes estadísticas del divorcio. Nos Divorciamos.com. http://www.nosdivorciamos.com/?q uien=bW9kdWxvPWludGVybmEmdGFibGE9YXJ0aWN1bG8mb3BjaW9uPTE3.

2 Fuente: Estadísticas de Divorcio en Argentina. Dejate Sorprender http://dejatesorprenderradio.blogspot.com. $\operatorname{ar} / 2011 / 03 /$ estadisticas-de-divorcio-en-argentina.html.

3 Fuente: Hay un divorcio cada media hora. Infobae. 17-09-2013. http://www.infobae.com/2013/09/17/1509409hay-un-divorcio-cada-hora-y-media.

4 Fuente. Himitian, E. "Hubo mas de medio millón de divorcios en la última Década". La Nación. 04 Marzo 2012. http://www.lanacion.com.ar/1453694-hubo-mas-de-medio-millon-de-divorcios-en-la-ultima-decada.

5 Fuente: Separación o Divorcio después de las Vacaciones. Consulta Psicológica Madrid. http://www.consultapsicologicamadrid.com/separacion-o-divorcio-despues-de-las-vacaciones/. 


\section{Sociología del divorcio}

Uno de los primeros sociólogos en abordar el tema de la desintegración social ha sido el francés Emile Durkheim. En toda su obra, se hace foco en el rol de la religión como factor cohesionador de las relaciones humanas. A través de la lectura del legado de Fustel de Coulange, quien había observado como en la ciudad antigua los lazos iban debilitándose a medida que la devoción religiosa declinaba, Durkheim sostiene que una nueva organización del trabajo (industrialismo) pone en crisis los valores de la civilización occidental. El lazo social cede frente a otros mediadores como ser la ley civil, el trabajo y el dinero (Durkheim, 1997; Giddens, 1971; 1992). Desde entonces, muchos sociólogos han apuntado a una "descomposición del lazo" en los grandes centros urbanos. Las antiguas formas de poder, que eran las aristocracias políticas, se han debilitado hasta crear una horizontalidad que pone a todos los ciudadanos en igualdad de condiciones frente a la hegemonía del comercio (Baltzell, 1991; Nisbet, 1993; Putnam, 1995; Castel, 1997; Sobel, 2002; Hardt y Negri, 2009). Dentro de este contexto, la ruptura del matrimonio o divorcio sería uno de los indicadores de la descomposición social de la era (pos)industrial. Denis Merklen (2013) sugiere que si bien las instituciones siguen funcionando, lo que se ha cambiado es la manera en la cual se producen las respectivas subjetividades. En constante competencia con los demás y consigo mismo, el ciudadano moderno es educado para ser gestor de su propia biografía, para aceptar los riesgos, costos y beneficios de la inestabilidad económica. Adentrarse al futuro y cuestionar todo lo conseguido parece ser una de las cuestiones o aspectos más representativos de la modernidad tardía. La movilidad impuesta sobre el mercado laboral denota la habilidad del trabajador para adaptarse a nueva situaciones y controlarse para hacer valer su subjetividad. A grandes rasgos, lo que ha cambiado según Merklen, es el proceso de individuación, en donde el sujeto, y ya no la sociedad, se transforma en gestor de su propio destino.

Inglehart (1997) sostiene que las sociedades adaptan sus sistemas económicos acorde a una interacción con el medio. En la medida que la sociedad feudal pasa a la industrial, las normas e instituciones se reciclan. Lo mismo sucede, actualmente, cuando las sociedades modernas entran en la posmodernidad. La industria de los servicios como el turismo o los medios masivos de comunicación, es uno de los aspectos incuestionablemente distintivos de la modernidad. La posmodernidad tiende no solo a erosionar los vínculos, sino los canales jerárquicos de autoridad. Eso supone que la postura posmoderna es más democrática que la moderna. Por ende, Inglehart traza un esquema de doble grilla acorde a sociedades cuyos valores están orientados a la supervivencia, respecto a sociedades centradas en el bienestar. A su vez, pone otras dos grillas horizontales: a) autoridad secular-racional y b) autoridad tradicional religiosa. Entre sus características más importantes están

\author{
Sociedad Tradicional \\ Confianza en Dios \\ Orgullo Nacional \\ Respeto por la autoridad \\ Respeto por los padres \\ Lazos fuertes \\ Importancia del trabajo
}

Sociedad Secular
Auto motivación y competencia
Compromiso en política
La política es importante
Autoriza divorcio
Permite el aborto
Trabajo prescindible

Las sociedades centradas en un sistema de bienestar y de autoridad secular tienden a tener familias con menos hijos que las tradicionales. De la misma manera, las sociedades seculares parecen haber desarrollado mayor propensión por el divorcio, y las prácticas sexuales (Inglehart, 1997). En perspectiva, existe una relación sustancial en las sociedades seculares entre el ocio y el divorcio que merece ser analizada. 
Por su parte los sociólogos Zygmunt Bauman, Rosenberg y Arrambide (2005) establecen un quiebre epistémico en las formas productivas de trabajo y producción. Anteponiendo metafóricamente la oposición entre lo sólido y lo líquido, Bauman explica que los lazos sociales tienden a debilitarse debido a tres factores principales: un cambio radical en los factores y líneas de producción, la descentralización de la autoridad jerárquica, la inmediatez como forma de relación humana (Bauman, 2011). La modernidad, en su argumento, ha generado un debilitamiento general en los sistemas simbólicos que le dan seguridad al ser humano, y que por sobre todo, le permitían planificar su vida a largo plazo. En esta nueva condición, el éxito parece condición de sacrificio por medio del cual el olvido y el divorcio se presentan como dos alternativas tangibles. Instrumentalizados sólo por sus beneficios comparables, los lazos sociales y las relaciones duraderas evidencia una falta de lealtad restringida hacia el consumo masivo (Vázquez Rocca, 2008).

Christopher Lasch (1991) introduce el término "cultura narcisista" para explicar no solo el debilitamiento de los lazos parentales y familiares, sino el apego desmedido respecto a los hijos. Las diversas frustraciones que el hombre moderno experimenta se vinculan a un sobre-valoración del vínculo con el hijo. Pero paradójicamente, el "homo consumer" tiene menos tiempo para dedicarles a sus hijos. A la vez que los divorcios se muestran como salidas cada vez más rápidas a las crisis de pareja, la obsesión se dirige hacia el vínculo filial. Como patología social propia del capitalismo, el narcisismo lleva a pensar al mundo circundante como caótico y peligroso. Ya nadie intenta encontrar soluciones a los problemas conjuntos, sino garantizar la supervivencia individual. La aceptación de otros es la pieza fundamental que ayuda a comprender como funciona el narcisismo en la vida cotidiana. La imagen grandilocuente del yo necesita de la liberación de los vínculos familiares que la contienen y restringen. Empero, como resultado se abre la puerta a una paradoja existencial, pues el hombre emplea a la unidad familiar como forma de protección frente a otros, rota esa unidad, su vida se torna más insegura e inestable. El narcisismo transforma el amor de otros, en odio de sí mismo. Producto de su impotencia, se lanza al mundo embriagado en un sentimiento generalizado de superioridad. Todos los dispositivos institucionales modernos en educación y en lo que respecta al mercado, se encuentran orientados a replicar una personalidad puramente narcisista, pues destruyen el vínculo con los otros. Empero, no todas las voces parecen tan críticas como las de Lasch o Bauman. Anthony Giddens (1992) argumenta convincentemente que el industrialismo y la modernidad mejoraron notablemente las cuestiones sanitarias de la población y las expectativas de vida. Las mujeres fueron entre las principales beneficiadas debido a la gran tasa de mortalidad de la edad media durante el alumbramiento de los neo-natos. La medicina moderna no solo permitió que las mujeres vivieran más tiempo, sino que también modificó las pautas sexuales y las relaciones entre las parejas. La mujer salió al espacio público a disputarle al hombre su hegemonía, hasta ese momento incuestionable. La sexualidad biológico-reproductiva cedió a una nueva forma de placer por medio del sexo, a la cual el autor denomina la "sexualidad plástica. La disputa de poder por parte de las mujeres también trajo consigo un aumento significativo en la violencia de género, por medio de la cual se intenta reprimir el ascenso social femenino.

\section{La Imagen idealizada del Turismo}

El estudioso de las religiones comparadas, Mircea Eliade asume que los mitos sociales forman sentidos específicos que ayudan a interpretar las prácticas. Toda sociedad debe validar dentro de un laso de tiempo, sus normas, y estatutos para poder continuar existiendo. El sentido último de la autoridad se corresponde con el éxito en estos procesos de renovación cosmológicos. Los grupos humanos recurren a los ritos de pasaje como desplazamiento liminares que obligan al hombre a romper con su rutina, con sus normas, para ser socializado en una nueva realidad (Eliade, 2005). E. Cohen fundamenta que las sociedades industriales 
han creado paraísos fabricados, emulando al cielo perdido que sólo adquiere importancia en la restricción misma. Ello sugiere que el destino turístico moderno emula al cielo no solo por la fastuosidad del consumo que genera un quiebre abismal respecto a la vida en la lógica del trabajo, sino también debido a su exclusividad (Cohen, 1982). Joseph Campbell revela que el origen semiológico de la palabra paraíso deriva del persa Pairi (circundante) y Daeza (espacio prohibido). Esta combinación, sustentada por los textos sagrados la Biblia o el Talmud, enfatiza en un paraíso dado originalmente al hombre y retirado de su dominio por la caída original. Desde entonces, el retorno constante ese estado de placer continúo se ha transformado en una de las obsesiones de la cultura occidental (Campbell, 1968).

En este sentido, Korstanje \& Busby (2010) explican que el génesis del turismo nace con la Biblia misma en la sociedad Occidental. La creación del mundo anuncia que Dios sabe que su obra es justa y buena, entonces por eso descansa. En todo el antiguo y nuevo testamento existen elementos míticos que vinculan al pecado con la idea de "carga". La expiación de los pecados por medio del rito bautismal retoma las cargas de la persona para poder sublimarlas en una renovación espiritual. Contemplando la naturaleza pecadora del hombre, este ciclo se hace renovable día a día. El mandato a "vacacionar" no solo encierra la misma lógica sino que emula los mismos valores. El trabajador debe deshacerse de su carga (tareas), para descansar (como Dios) y renovarse por medio del agua (el mar) y el fuego (sol). El éxito de este ritual garantizará su prosperidad para el próximo año. Existe un quiebre epistemológico en el turista que a la vez que intenta redimirse, acepta y renueva su confianza en la sociedad.

Marc Augé confiere al turismo el aura de industria de la fantasía o viaje imposible pues se nutre de formas estereotipadas donde no existe contacto genuino con el otro. Se remite a una idealización extrema, como un sueño, que nunca entra en contacto con la realidad hasta el regreso del veraneante. El viaje imposible se remite a ese desplazamiento, admite Augé, que no podemos hacer más, el descubrimiento. Circunscriptos a la hegemonía de lo visual, el turista viaje por donde le es permitido, precisamente por el territorio delineado cuidadosamente por la agencia de viajes para generar una experiencia, vendible y transferible a otros (Augé, 1998). Una revisión histórica de las "vacaciones" nos lleva a la costumbre del veraneo, propia de las clases altas europeas. Resultado de una serie de conquistas sindicales, este ritual comenzó a expandirse a otros grupos sociales menos privilegiados desde el siglo XIX en adelante. Funcional a la estratificación económico-social, el veraneo sentó las bases para una verdadera "democratización" del ocio para crear un nuevo entramado social y político (Pastoriza, 2011). Sin embargo, no todos coinciden en ver al turismo como un agente democratizador. Korstanje (2012) critica a Pastoriza por confundir democratización con masificación. El turismo tal y como lo describe Pastoriza expandió sus fuerzas productivas fuera de las fronteras de los estados nacionales y las marcas de clase, pero no por eso fue más democrático (Pastoriza, 2011). Siguiendo a Tim Ingold, el turista trabaja todo el año para producir un capital que le es ajeno, y como contrapartida compromete su propio ingreso en pos del descanso. De esta manera, el capital fluye y vuelve siempre al mismo origen, el dueño del aparato productivo, en donde el trabajador es un engranaje pequeño (Ingold, 2000; 2011)

Dean Maccannell propone que el turismo permite crear un discurso "meta pragmático" para legalizar la producción económica. Nadie puede escapar al ser turista, hasta el punto de quedar en la ilusión del regreso. El espacio de ocio urbano que facilita la práctica turística se manifiesta como un mecanismo de "alienación" y cosificación del trabajador moderno. La emancipación que implica el turismo de la rutina del trabajo, no es una ruptura sino un nivelador que permite al trabajador estar en condiciones de ser reintegrado a la línea de montaje. Si el mundo racional del trabajo se caracteriza por una supresión sustancial de las emociones humanas, el turismo se contrapone exacerbándolas. Sin embargo, ambos mundos son parte integrante del mismo fenómeno. Tal y como se dio la escenificación del trabajo en las 
fabricas de automóviles del siglo XIX y XX, el turismo confabula junto a la modernidad en detrimento de la autenticidad del vínculo (manipulando al trabajador y convirtiéndolo en un títere del consumo) (Maccannell, 1988, 2003, 2007)

El antropólogo Víctor Turner estableció la tesis de las crisis "de los ciclos vitales como una forma de renovación de las relaciones humanas. El mundo social, según su visión, se encuentra estructurado en tramas simbólicas, y no en procesos económicos. Se dan patrones y factores específicos que ayudan a darle interpretación a los símbolos, los cuáles se dan en dos tipos, dominantes, y pasivos. Los primeros confieren un valor y significado no solo a los objetos y a las personas, sino a los usos que deben hacerse de ellos. Cada ritual y su respectiva performance combinan crisis con mecanismos de ajustes que le devuelven a la sociedad el equilibrio. Los ritos de las crisis vitales están vinculados a cualquier cambio físico, psíquico o social del individuo como ser un nacimiento, un pasaje a otro clan, la llegada de la pubertad, o la muerte de un familiar. Esta clase de ceremonias, también son observables en las sociedades occidentales. En estos procesos, el individuo cambia su estatus y es reconducido a un nuevo estado en donde debe relacionarse con otros actores -hasta ese entonces lejanos para él. Por otro lado en los rituales de iniciación, los individuos son en primer lugar separados de su grupo de pertenencia habitual, y recluidos durante un tiempo sin contacto alguno con otros o sólo entre los "iniciados". Luego de un tiempo que el grupo considera "prudencial" y en donde se los re-socializa con nuevas enseñanzas, son re-ubicados e insertos en su nuevo grupo; en todo viaje iniciativo existen dos cosmologías, dos imágenes en pugna, la nueva y la anterior. Para que el ritual tenga éxito, el sujeto debe adaptarse al nuevo mandato, dejando atrás su pasado como niño (Turner, 1999).

Algunos especialistas como Graburn (1983), Krippendorf (2009), Dos Santos (2005), Hiernaux (2000) y Lacanau (2003) afirman que todo viaje implica un cambio de normas, lo cual no implica sólo moverse, sino adentrarse en espacios que eran desconocidos. Este tránsito temporal despierta una crisis existencial que es trabajada desde la experiencia. Desde esta perspectiva, el turismo debería ser considerado un rito de pasaje por medio del cual el sujeto es voluntariamente dirigido a un espacio liminar de placer y hedonismo, para luego ser re-socializado en un nuevo grupo de adscripción y pertenencia. Luego de cada viaje vacacional, no solo se renuevan las normas del nuevo grupo, sino que el turista ostenta la pertenencia a su nueva clase social. Ello explicaría, sin ir más lejos, porque muchas familias movilizan recursos financieros importantes en un consumo ostentoso cada año. Por último pero no por ello menos importante, M. Korstanje advierte que si bien el turismo puede ser considerado un ritual, es incorrecto atribuirle al iniciado (viajero) nuevas facultades o habilidades a su regreso. La crisis de ciclo vital es útil para entender los viajes de "egresados", pero no el turismo moderno por una razón primordial. El status del viajero no cambia a su regreso. El turista como generador de producción, invierte su ganancia en su descanso. Puede ostentar su nivel social, pero a su regreso formará parte del mismo peldaño social del cual partió. En concordancia con Eliade, Korstanje sugiere que el viaje turístico obedece a una naturaleza cíclica de construcción y renovación (Korstanje, 2009). En ese trabajo, de todos modos, Korstanje trivializa el rol del conflicto dentro del viaje de vacaciones, o por lo menos no lo toma seriamente en cuenta. En ese punto, el presente abordaje intenta ser un estudio superador.

\section{Estadísticas Comparadas.}

Una de las mayores dificultades a la hora de comprender y medir el divorcio es la brecha temporal entre la ruptura real, y la fecha en que se inicia el trámite legal. Las estadísticas vigentes en la Ciudad de Buenos Aires, si bien comprende a todos los casos de "divorcios vinculares" registrados, adolece de datos que describan la fecha de ruptura. No obstante, consideramos que la información suministrada es fidedigna si se examina mes a mes. La 
muestra analizada comprende información censal, es decir el 100\% de todas las demandas iniciadas por divorcio en la ciudad entre el año 2012. Por tratarse de organismos estatales, la presentación y elaboración estadística que se encuentra sujeta a cambios de metodologías de un periodo respecto a otro. Por ese motivo, y en vistas del origen de las hipótesis, consideramos necesario no implementar un seguimiento histórico de las tasas de divorcio, sino simplemente circunscribirnos en los últimos dos años, cuya compatibilidad de método garantiza la lectura de la información.

\section{Tabla 1}

Divorcios según estado civil de los cónyuges anterior al matrimonio que se disuelve. Ciudad de Buenos Aires. Año 2012

\begin{tabular}{|c|c|c|c|c|c|}
\hline Estado civil & Estado & interior & cónyug & & \\
\hline $\begin{array}{l}\text { anterior (de } \\
\text { cónyuge) }\end{array}$ & Total & Soltera & Viuda & Divorciada & Ignorado \\
\hline Total & 5.866 & 5.447 & 36 & 361 & 22 \\
\hline Soltero & 5.290 & 5.068 & 19 & 193 & 10 \\
\hline Viudo & 45 & 24 & 1 & 20 & - \\
\hline Divorciado & 517 & 351 & 16 & 148 & 2 \\
\hline Ignorado & 14 & 4 & - & _ & 10 \\
\hline
\end{tabular}

Fuente: Dirección General de Estadística y Censos (Ministerio de Hacienda GCBA). Estadísticas vitales.

La Tabla número 1 demuestra que de un total de 5.866 divorcios registrados en 2012 , una mayor cantidad de cónyuges mujeres se encuentra casada en primeras nupcias. Unos 5.068 casos correspondes a mujeres anteriormente solteras, mientras apenas 361 se encuentra casada por segunda vez. Las divorciadas representan 36 casos. Lo mismo sucede con el cónyuge varón. De un total de 5866 casos, 5.290 involucran a un hombre soltero, mientras los anteriormente divorciados son 517 casos. Los datos revelados sugieren una primera hipótesis tentativa, la mayor cantidad de divorcios puede deberse a causas vinculadas a la inexperiencia. Para poder profundizar en esta cuestión es importante desagregar la misma información por grupo de edad.

La tabla 2 infiere que de un total registrado de 5.866 divorcios, 1.206 se disuelven dentro de los 9 años, mientras 1.924 entre 10-19 años y sorpresivamente, 2.161 más de 20 años. La idea de la inexperiencia, entonces, se cae en vistas de los números. La mayor cantidad de divorcios registrados obedecen a parejas con más de 20 años de casados. Existe una clara tendencia a la descomposición del lazo como enuncia la literatura especializada. En estos términos, los rangos comprendidos entre 35/39 años registran la cantidad más importante de divorcios con 1.139 casos, seguidos de 40/44 con 1.003, y 45-49 con 910. Los datos no autorizan a confirmar una dirección unívoca de la tendencia. Por lo tanto, para validar la hipótesis del estrés post-vacacional, es necesario nuevamente analizar la información por mes de iniciado legalmente el divorcio. 


\section{Tabla 2}

Divorcios según grupo de edad de la cónyuge y duración del matrimonio que se disuelve. Ciudad de Buenos Aires. Año 2012

\begin{tabular}{llllll}
\hline \multirow{2}{*}{ Grupo de edad (años) } & \multicolumn{2}{l}{ Duración matrimonio que se disuelve (años) } & $5-9$ & $10-19 \begin{array}{l}20 \\
\text { más }\end{array}$ \\
\cline { 2 - 6 } Total & Total & Hasta 4 & $\mathbf{1 . 2 0 6}$ & $\mathbf{1 . 9 2 4}$ & $\mathbf{2 . 1 6 1}$ \\
$20-24$ & $\mathbf{5 . 8 6 6}$ & $\mathbf{5 7 2}$ & 13 & - & - \\
$25-29$ & $\mathbf{3 0}$ & 17 & 121 & 18 & - \\
$30-34$ & $\mathbf{2 6 2}$ & 123 & 384 & 205 & - \\
$35-39$ & $\mathbf{8 1 6}$ & 227 & 398 & 605 & 18 \\
$40-44$ & $\mathbf{1 . 1 3 9}$ & 118 & 162 & 607 & 203 \\
$45-49$ & $\mathbf{1 . 0 0 3}$ & 31 & 63 & 276 & 550 \\
$50-54$ & $\mathbf{9 1 0}$ & 21 & 21 & 113 & 583 \\
$55-59$ & $\mathbf{7 2 9}$ & 12 & 18 & 52 & 365 \\
60 y más & $\mathbf{4 4 5}$ & 10 & 15 & 36 & 435 \\
Ignorado & $\mathbf{4 9 5}$ & 9 & 11 & 12 & 7 \\
\hline
\end{tabular}

Ta diferencia con el total se debe a casos de duración del matrimonio que se disuelve ignorada

Fuente: Dirección General de Estadística y Censos (Ministerio de Hacienda GCBA). Estadísticas vitales.

\section{Tabla 3}

Divorcios vinculares inscriptos en el Registro Civil. Ciudad de Buenos Aires. Enero/diciembre 2012

Mes Divorcios vinculares inscriptos

\begin{tabular}{ll}
\hline $\mathbf{2 0 1 2}$ & 5.866 \\
Enero & 216 \\
Febrero & 359 \\
Marzo & 609 \\
Abril & 477 \\
Mayo & 552 \\
Junio & 572 \\
Julio & 402 \\
Agosto & 527 \\
Setiembre & 488 \\
Octubre & 604 \\
Noviembre & 536 \\
Diciembre & 524 \\
\hline Nota: los valores son de carácter provisorio y sujeto a las modificaciones propias de los procesos del Sistema \\
de Estadísticas Vitales en vigencia. \\
Fuente: Dirección General de Estadística y Censos (Ministerio de Hacienda GCBA). \\
Estadísticas Vitales
\end{tabular}


En Enero de 2012 se registraron apenas las tasas mas bajas con 206 casos, seguidos en Febrero de 359. Empero ese número se duplica en Marzo con 609 casos (valor máximo del año). Es curioso observar que nuevamente la tasa vuelve a mostrarse elevada durante Octubre con 604, Noviembre 543 y Diciembre 524. En parte puede afirmarse que las vacaciones juegan un rol importante como efecto disgregador de la pareja, empero si agrupamos la información por trimestres ene/feb/mar contra oct/nov/dic, comprenderemos mejor el fenómeno.

El primer trimestre registra una sumatoria de 1.184 trámites, mientras el último trimestre muestra un número significativamente mayor 1.664 trámites. Según esta información, no son las vacaciones en sí lo que genera mayores divorcios, sino las fechas claves. Partiendo de la premisa que la mayor cantidad de divorcios se registra en los meses anteriores a fin de año y Navidad, en números acumulados la gente tiende a separarse más antes de las Fiestas, que luego de las vacaciones. Las rupturas liminares que representa el fin de año y las vacaciones aceleran los procesos de crisis iniciados en la pareja por la modernidad. Como verdaderos ritos de pasaje, ya sea la celebración de un nuevo año como el inicio del proceso de receso, generaría diversos conflictos dentro de la pareja que de no ser coherentemente regulados podrían culminar en la separación marital. Si bien estos números no son suficientes para tomar conclusiones definitivas, inician en punto de convergencia para futuras investigaciones. La disonancia entre el mundo del trabajo y del turismo (estrés post-vacacional) no sería la variable única de las altas tasas de divorcio registradas como asume informalmente la psicología de pareja. No es el viaje (como sume Turner), sino la importancia conferida al ritual lo que predispone a la crisis.

\section{Conclusión}

La evidencia presentada sugiere que los viajes de vacaciones no son generadores por si mismos de división marital, sino por la expectativa que ellos generan. No es el stress al cual inducen estos viajes el único aspecto que influye en los divorcios, sino lo que turner llamó "crisis de los ciclos vitales". Comprendiendo al turismo, pero también a fin de años como procesos de renovación productiva donde se agradece a los Dioses por la prosperidad otorgada, existe la posibilidad de generar una gran ruptura. Si el lazo social no es lo suficientemente fuerte, es posible que los grandes eventos generen, de alguna manera que no se puede precisar en el presente estudio, disgregación y aislamiento. Los conflictos pre-existentes dentro del seno familiar se agudizarían en año nuevo y durante las vacaciones. La tendencia mundial al divorcio no solo es innegable, sino que acusa recibo de una desagregación de lo social en la vida moderna. Si bien los resultados de esta investigación, son exploratorios, su fiabilidad se encuentra determinada por la característica censal de la muestra. El universo escogido representa la totalidad de casos de divorcios registrados en el Registro Civil de la Ciudad de Buenos Aires para el año 2012. Debido a que en Argentina las oficinas estadísticas cambian su método con frecuencia, es que no es posible indagan en evoluciones históricas de las diversas tasas de divorcios.

\section{Bibliografía}

AUGE, M.

1998 El viaje imposible: el turismo y sus imágenes. Barcelona, Editorial Gedisa

BAUMAN, Z., ROZENBERG, M., \& ARRAMBIDE, J.

2005 Amor líquido. México DF: fondo de cultura economica.

BAUMAN, Z.

2011 Amor líquido: acerca de la fragilidad de los vínculos humanos. Fondo De Cultura Economica. 
BALTZELL, D. E

1991 The Protestant Establishment revisited. New Bunswick, Transaction Publishers.

CAMPBELL, J.

1968 The Masks of God. vol.1 Primitive Mythology. London: Secker and Warburg.

CASTEL, R.

1997 Las metamorfosis de la cuestión social: una crónica del salariado. Buenos Aires, Paidós. COHEN, E.

1982 "The Pacific Islands, from utopian myth to consumer Product". The Disenchantment Paradise. Cathiers du Turisme, Serie B. 27

DOS SANTOS, J. R.

2005 "Antropología, comunicación y turismo: la mediación cultural en la construcción del espacio turístico de una comunidad de pescadores en Laguna, Sc. Brasil”. Estudios y Pers-

DURKHEIM, E. pectivas en Turismo. Volumen 14. Número 4. Pp: 293:313.

1997 The division of labor in society. New York, Simon and Schuster.

ELIADE, $\mathrm{M}$.

2006 The myth of the eternal return: Cosmos and history (Vol. 46). New Jersey: Princeton University Press.

GIDDENS, A.

1971 Capitalism and modern social theory: An analysis of the writings of Marx, Durkheim and Max Weber. Cambridge, Cambridge University Press.

1992 The transformations of intimacy. Cambridge: Polity.

GRABURN, N. H

1983 the Anthropology of Tourism. Annals of Tourism Research. Vol. 10 (1)

HARDT, M., \& NEGRI, A.

2009 Empire. Massachusetts, Harvard University Press.

HIERNAUX, N.

2000 "La fuerza de lo efímero". En Alicia Lindon Villoria (comp). La vida cotidiana y su espacio-temporalidad. México: Editorial Anthropos.

INGLEHART, R.

1997 Modernization and Postmodernization. Cultural, economic, and political change in 43 societies. New Jersey, Princeton University Press.

INGOLD, T.

2000 The Perception of Enviroment: essays on livelihood, Dwelling and Skill. London, Routledge.

2011 Being Alive. Essays on movement, knowledge and description. London, Routledge.

KORSTANJE, M.

2009 "Interpretando el Génesis del Descanso: una aproximación a los mitos y rituales del turismo". Pasos. Revista de Turismo y Patrimonio Cultural, 7(1), 99-113.

2012 “Reseña: la conquista de las vacaciones". Pasos. Revista de turismo y Patrimonio Cultural. Vol 10 (1): 217-220

KORSTANJE, M \& BUSBY, G.

2010 Understanding the Bible as the roots of Physical Displacement. The Origin of tourism. KRIPPENDORF, J E-Review of Tourism Research. Vol. 8 (3): 95-111

2009 Sociología do turismo. Para uma nova comprensao do lazer e das viagens. Sao Paulo LACANAU, G.

2003 "El rito sagrado de las vacaciones: alimentos y género en la Argentina de 1930-1950". Gastronomía y Turismo: cultura al plato. Lacanau G y Norrild J (comp). Buenos Aires: LASCH, C. CIET. Pp: 203-216.

1991 The culture of narcissism: American life in an age of diminishing expectations. New York, WW Norton. 
MACCANNELL, D.

1988 "Turismo e Identidad cultural”. En Todorov, Tzvetan. El Cruzamiento entre culturas. Madrid, Ediciones Jucar"

2003 El Turista: una nueva teoría de la clase ociosa. Barcelona, Melusina Ed.

2007 Lugares de Encuentro Vacío. Barcelona, Melusina Ed.

MERKLEN, D.

2013 "Las Dinámicas contemporáneas de la individuación”. En Individuación, precariedad, inseguridad. Buenos Aires, Paidos, pp. 45-77

NISBET, R. A.

1993 The sociological tradition. New Burnswick, Transaction publishers.

PASTORIZA, E.

2011 La Conquista de las Vacaciones. Breve historia del turismo en Argentina. Buenos Aires, Edhasa.

PUTNAM, R. D.

1995 Bowling alone: America's declining social capital. Journal of democracy, 6(1), 65-78.

ROCCA, A. V.

2008 Zygmunt Bauman; Modernidad Líquida y Fragilidad Humana. Observaciones filosóficas, SOBEL, J.

2002 Can we trust social capital?. Journal of economic literature, 40(1), 139-154.

TURNER, V.

1999 La selva de los símbolos. Madrid: Siglo XXI.

\section{3}

